\title{
Sino-French Engineering Curriculums: An Ongoing Process for Elitist Education?
}

\author{
Richard Mariom \\ Social sciences Institute, University of Lausanne, University of Lausanne, UNIL, Lausanne, Switzerland \\ Email: Richard.marion@unil.ch
}

Received 2012

\begin{abstract}
Here is a multisite case-study paper presenting Sino-French engineering education reform cooperation process. This questions the consequences for the introduction of a hybrid framework in a both dynamic and dichotomous innovation context such as Chinese one.
\end{abstract}

Keywords: Component, French Style Engineering/’Grandes éColes’; Adjustments; Translations; Perceptions; Discourses; Practices

\section{Introduction}

It has been 15 years that Sino-French engineering education is emerging in China. Starting on Chinese Minister of Education's initiative, what the projects are about is importing the very French style engineering 'grandes écoles', meaning prestigious graduate engineering schools expected to educate coming leaders and decision makers in the field of engineering as well as in finance, entrepreneurship or higher civil service positions. The purpose is to implement such institutes within Chinese higher education system, bringing alleged elitist French know how: selection, studying and working pace, broad based education...

\section{Theoretical Framework}

This multisite case-study paper offers to be part of social studies of science, more precisely relying on sociology of translation works in the vein of Michel Callon and Bruno Latour. Trying to think such a highly hybrid as China's Sino-French engineering education platforms, I will rely the theorization part of my analysis on Rigas Arvanitis’ works, showing China's major gap is trust lacking between industrial, public research, universities and administration actors[1]. Indeed, actor-network theory implies that links play a bigger role than actors themselves, regardless of how powerful they might be. China is becoming good at attracting physical as well as human top quality capitals. But they still tend to work apart from domestic ones, leading to two largely autonomous types of technological development, as identified by Zhao Wei[2]. Thus, analyzing Sino-French curriculums as seen through the eyes of the translation sociologist will enlighten our understanding of connections so as to to catch who trusts who, and how.

\section{Methodology}

My point is to get a deeper comprehension of what originators of these projects intended to do compared with what actually happens. Here is a paper based on a multisite case study analyzed thanks to two field-works led in mainland China (from May to August 2009 and March to June 2011), enabling to get 28 semi-structured interviews on three campuses located in Beijing, Shanghai and Guangzhou. Thus, I could respectively analyze Beijing Central Graduate School, Shanghai SinoFrench Institute for Engineering and Management and SinoFrench Institute for Nuclear energy in Zhuhai (Guangdong). I have met most of the persons in charge on the French as well as on the Chinese side, including some industrialists. As a counterpoint, I also visited and met a German manager for the Sino-German Center in Tongji University.

First, strategic goals have to be clarified and organized for such massive long-term investments (annually millions of euros, key technologies knowledge and know how sharing). Compared with Chinese requests, French counterparts have responded for many reasons and with many different frames of mind as an original windfall effect as far as French managers of Sino-French institutes behave like campaigners, supporting the education subsystem they actually grew up inside. What matters here is also about French foreign policy, French language promotion, and education of high skills workforce French companies do miss in China. As a consequence, our analysis goes about Chinese bureaucracy as well as Chinese students' sociology or Chinese companies' requests and non-requests, which is noteworthy.

Even if Sino-French engineering education has been strongly backed up by Chinese as well as by French governments, what it relies on within society is quite different. Not meaning Chinese industry will get no benefit from such a qualified work force, it has to be noticed that French demand pull dynamic contrasts with Chinese political push. That's why the cooperation process, though quite dynamic, and somehow balanced, works through organizational asymmetry, mostly relying on industrialists on the French side while it is still political and administrative business in China.

Second, each others' discourses need to be compared between them and to the emerging reality of Sino-French education in China. Listening to Chinese leaders as well as their French counterparts, the story seems to run as if French engineering schools had been designed centuries ago to cooperate and to become integrated institutes into Chinese traditional university frame. However, capacity for adaptation indeed ap- 
pears as a rising issue so as to make it possible to build French style education programs sticking to Chinese current environment.

\section{Preliminary Results}

As a matter of fact, French engineering education tradition is part of an ongoing bargaining, recasting, translating process aiming at building mutual confidence. Several key issues have been reshaped in the field of organizational behavior, budget sharing as well as teaching strategies. Involved actors actually behave according to their best interest and their own subjective conception of what and how higher education should target 'professional engineers' as it keeps on being repeated.

Such an entanglement of Sino-French various partners raises many questions among which only a few actually takes a part in agenda setting: who precisely should pay for education of Chinese engineers? What relative positions and goals are to be attributed to Chinese, English and French languages within a risingly multilingual teaching, studying and working context? Managers in charge of Sino-French engineering institutes also have to deal with numerous very practical issues resulting from know how transposition, reshaping and building processes. Here stand soft but powerful change factors for engineering education style.

\section{Contribution and Significance of Research}

Part of the process led to important shifts, out of French managing team's will as well as their Chinese counterparts, namely as critical spirit is at the heart of the educational project, within and about Sino-French engineering teaching frame. In the final analysis, this case-study paper questions the consequences for the introduction of a hybrid framework in a dichotomous innovation context as far as the hybrid is to design, displace and, thus, redesign a wider network for innovation in China, which is explicitly Chinese government's medium term strategy. That's why engineering visions are to be part of a broader comprehension of social context highlighting a kind of interlocal socio-technical hybrid.

\section{REFERENCES}

Arvanitis Rigas and Ruffier Jean, 2008 : L’inégal développement industriel de la Chine : capacités d'innovation et coexistence de différents modes d'apprentissage technologique in Région et développement, numéro 28, Paris : L’Harmattan.

Zhao Wei, 2006 : Économie de l'innovation et développement des capacités technologiques en Chine, Thèse pour le doctorat à l’Université Paris III, sous la direction du Professeur Xavier Richet. 